\title{
PERCEPÇÕES SOBRE APRENDIZAGEM E USO DE LÍNGUA PORTUGUESA POR INDÍGENAS VENEZUELANAS DA ETNIA WARAO REFUGIADAS EM PACARAIMA/RR
}

\author{
PERCEPTIONS ON LEARNING AND USE OF PORTUGUESE LANGUAGE \\ BY VENEZUELAN WARAO INDIGENOUS REFUGEES IN PACARAIMA/ \\ $R R$
}

\author{
Isis Pereira dos Santos ${ }^{1}$ \\ Cora Elena Gonzalo Zambrano ${ }^{2}$
}

\section{Resumo}

Este artigo objetiva analisar a necessidade de uso e aprendizagem da língua portuguesa por mulheres refugiadas venezuelanas indígenas da etnia Warao. Realizou-se uma pesquisa de campo com um grupo de vinte mulheres artesãs do abrigo indígena Janokoida, localizado em Pacaraima/RR, município de fronteira com a Venezuela. A problematização foi levantada no ambiente multilíngue de contexto migratório e fronteiriço a partir das percepções quanto à necessidade de aprendizagem e do uso da língua portuguesa. O estudo lançou mão da pesquisa-ação através de oficinas de ensino de português oferecidas às artesãs. A técnica de observação participativa foi importante para analisar o contexto das práticas linguísticas e o funcionamento do abrigo. Após uma análise qualitativa, os resultados indicaram diferentes percepções quanto ao interesse pela aprendizagem de português, como o uso da língua por necessidade comercial ou o não uso por resguardo de suas referências identitárias e pela intenção de curta permanência em território brasileiro.

\section{Palavras-Chave}

Aprendizagem. Língua Portuguesa. Refúgio. Indígenas Waraos.

\begin{abstract}
This article aims to analyze the need for use and learning of the Portuguese language by indigenous Venezuelan refugee women of Warao ethnicity. A field research was conducted with a group of twenty women artisans from the Janokoida indigenous shelter, located in Pacaraima / RR, a municipality bordering Venezuela. The problematization was raised in the multilingual environment of migratory and border context from the perceptions about the need for learning and the use of the Portuguese language. The study used action research through Portuguese language workshops offered to artisans. The participatory observation technique was important for analyzing the context of language practices and the functioning of the shelter. After a qualitative analysis, the results indicated different perceptions regarding the interest in learning Portuguese, such as the use of the language for commercial necessity or the non-use for the protection of its identity references and the intention of short stay in Brazilian territory.
\end{abstract}

\section{KEYWORDS}

Learning. Portuguese Language. Refuge. Waraos Indians.

1 Especialista em Ensino de Línguas em Contexto de Diversidade Linguísticas pela Universidade Estadual de Roraima.

2 Doutoranda em Estudos Linguísticos pela Universidade Federal de Minas Gerais, professora da Universidade Estadual de Roraima. 


\section{INTRODUÇÃo}

Diante da repercussão do fenômeno migratório e o grande impacto social no município de Pacaraima, localizado ao norte de Roraima, na fronteira com a Venezuela, surgiu a necessidade de criação de um espaço para abrigo, atendimento/acolhida dos indígenas da etnia Warao, os quais ocupavam as ruas do município e se encontravam em grave situação de exposição a riscos, ampla vulnerabilidade e rejeição social. A partir de novembro de 2017, por intermediação de ações colaborativas e compartilhadas de entidades do Governo Federal, do Governo do Estado de Roraima, da Prefeitura Municipal de Pacaraima e da Organização das Nações Unidas - ONU, foi criada a Casa de Passagem de Pacaraima - CPP (carinhosamente batizada com o nome Abrigo Janokoida). ${ }^{3}$

Até o mês de novembro de 2018 o Abrigo Janokoida atendia cerca de 470 pessoas através da Secretaria de Estado do Trabalho e Bem-Estar Social de Roraima (SETRABES) e da Prefeitura Municipal de Pacaraima, com o apoio do Exército do Brasil (Ministério da Defesa e Ministério das Relações Exteriores), financiamento do Governo Federal através do Ministério do Desenvolvimento Social (MDS) e intermediação do Alto Comissariado das Nações Unidas para os Refugiados (ACNUR/ONU). Nesse mesmo ano trabalhei (autora principal deste trabalho) durante seis meses como servidora seletivada pela SETRABES, ocupando o cargo de agente sócio-instrutora, função na qual desenvolvia práticas de ensino da língua portuguesa e mediação de atividades socioeducativas.

Durante esse período foi possível perceber que as oportunidades para integração social das mulheres indígenas junto à localidade de Pacaraima estavam notoriamente reduzidas, tendo em vista que a grande maioria procurava se comunicar através da língua Warao (doravante LW) ou em Espanhol (doravante LE), sem tentar falar a língua Portuguesa (doravante LP). Mesmo em contexto cotidiano de contato e convivência multilíngue se observava que havia diferenças entre os grupos de indígenas (crianças, homens e mulheres) quanto ao interesse ou ausência de interesse em aprender ou usar a língua portuguesa, situação que despertou a motivação para pesquisar o tema da aprendizagem e do uso da língua portuguesa por refugiadas indígenas, mais especificamente pelas mulheres Warao dentro do Abrigo Janokoida, de modo a compreender as necessidades de comunicação dessas pessoas e se manifestavam interesse em fazer uso da língua portuguesa. Nesta perspectiva, a pesquisa teve como base a seguinte problematização: Quais são as necessidades de aprendizagem e uso da LP por mulheres refugiadas indígenas da etnia Warao, abrigadas em Pacaraima/RR? A partir dessa problemática, planejamos (eu e minha orientadora que assina este artigo em coautoria) cinco oficinas sequenciais com práticas de uso da LP, voltadas para um grupo de vinte mulheres artesãs, moradoras do Abrigo Janokoida em Pacaraima, no intuito de concretizar as variáveis a serem analisadas. De modo que as aulas realizadas durante as oficinas e o registro das observações no cotidiano de convivência local foram norteadas pelas seguintes subperguntas de pesquisa: Como se dá o contato entre a Língua Portuguesa, a Espanhola e a Warao no abrigo? Quais aspectos de interesse as mulheres indígenas da etnia Warao apresentam quanto à necessidade do uso da língua portuguesa? Em quais ambientes as mulheres indígenas apontam esses interesses pela aprendizagem da LP?

3 Em língua indígena Warao Janokoida significa Casa Grande ou Grande Abrigo. 
A partir das subperguntas de pesquisa elaboramos o objetivo do estudo: analisar as necessidades de aprendizagem e uso da língua portuguesa de artesãs indígenas da etnia Warao em Pacaraima. Para chegar a tal objetivo, descrevemos o ambiente de contato entre as línguas portuguesa, espanhola e warao no abrigo Janokoida; posteriormente, identificamos aspectos de interesse ou necessidade que percebemos nas mulheres indígenas Waraos, com relação ao uso e à aprendizagem da língua portuguesa.

O estudo foi realizado no campo da Linguística Aplicada, que tem o objetivo de analisar fenômenos em situação de uso real da língua (MOITA LOPES, 1996). Assim, partimos das trocas vivenciadas nas práticas do ensino de língua portuguesa com mulheres artesãs indígenas, visando reflexões sobre nossas percepções quanto às necessidades desse público que está em situação de refúgio e convivência em abrigo brasileiro, em aprender ou não uma nova língua.

A pesquisa foi desenvolvida como trabalho de conclusão do curso da Especialização em Ensino de Línguas em Contexto de Diversidade Linguística (UERR). Os conceitos básicos foram apresentados a partir de referências encontradas em autores como: Almeida Filho (2002; 2007); Rajagopalan (1998); Agier (2009); Garcia Castro (2000), Matos (2004), dentre outros.

Metodologicamente a pesquisa foi qualitativa, com registros realizados a partir de pesquisa de campo (BORTONI-RICARDO, 2008), mediante a observação participativa (RICHARDSON, 2007) e o método de pesquisa-ação (THIOLLENT, 2013).

As ações desenvolvidas durante as oficinas e a observação participativa visavam atender pontos de convergência entre nossos questionamentos e as leituras e interpretações que foram surgindo. Assim, como resultado, o presente artigo foi dividido em várias seções. A primeira trata sobre a fundamentação teórica utilizada como referência para reflexões sobre o cenário diverso de contato linguístico e a aprendizagem e o uso da língua portuguesa em contexto intercultural; posteriormente, com base em Agier (2009), trazemos reflexões sobre a situação dos refugiados como sujeitos inseridos em um não-lugar; outra seção descreve as características culturais da etnia indígena Warao. Uma parte importante do trabalho é a metodologia, com informações sobre como a pesquisa foi desenvolvida, quais procedimentos e técnicas foram empregados, o cenário da pesquisa e a amostra dos sujeitos pesquisados, além da descrição do planejamento das oficinas de língua portuguesa com as artesãs indígenas da etnia Warao. Na penúltima seção trazemos a discussão e a análise a partir dos dados gerados e apontamos as percepções consideradas importantes para a pesquisa. Por fim, apresentamos as considerações finais.

A realização deste trabalho justifica-se por considerar que há relevância social e acadêmica para estudos voltados para grupos minoritorizados, que promovam novas leituras sobre o ensino e o uso da língua portuguesa como instrumento de integração social, especificamente no caso de imigrantes e refugiados. Contudo, esperamos ainda que o presente trabalho possa contribuir para novas leituras sobre os desafios das práticas de língua portuguesa por indivíduos em situação de refúgio, de maneira que possamos refletir também sobre o universo dos imigrantes indígenas e sua relação com uso da língua portuguesa em território nacional.

\section{LÍNGUA, DIVERSIDADE E INTERCULTURALIDADE}

Seguindo a concepção de linguagem como prática social, entendemos as atuações dos indivíduos que as realizam de acordo com suas necessidades contextuais e interacionais. Nesse sentido, 
a complexidade e a diversidade que constituem os indivíduos multilíngues lhes possibilitam utilizar recursos variados à medida que interagem através da comunicação.

Quando se trata de sujeitos em contextos de fronteira o ambiente é naturalmente propício ao multilinguismo devido ao contato entre diferentes línguas. Neste caso, essa visão potencializa-se, pois além de indivíduos em situação de refúgio em região fronteiriça, nossos sujeitos trazem em sua bagagem características étnico-culturais indígenas com repertório linguístico originalmente bilíngue, considerando o domínio da língua indígena warao e do espanhol venezuelano. São sujeitos construídos e desenvolvidos a partir das diferentes negociações em contexto situado do universo indígena de país hispano-falante que, com a imigração a um país cuja língua majoritária é o Português, pode incorrer em dinâmicas socioculturais que transcendem as circunstâncias do contato com outras línguas e culturas, promovendo um ambiente multicultural de comunicação.

Nesse sentido, para Matos (2004), o ensino da língua deve ser promovido objetivando-se a competência comunicativa dos aprendizes ou potenciais usuários, com metodologia mais humanizadora e promovendo práticas que ajudem os aprendizes no exercício de uma comunicação eficaz. A riqueza de diversidades na comunicação a ser vista nesse contexto não é a dos limites políticos, mas sobre aquelas relativas aos aspectos do pluralismo sob a égide do conceito de multiculturalismo, para dar vazão a novas abordagens e novas formas de ver, imaginar e perceber a importância das culturas e sua diversidade na composição daquilo que conhecemos como sociedades.

Nesse contexto, aprendizagem ou o uso de uma língua podem ser potencializados por abordagens comunicativas interculturais. Cada povo tem sua cultura composta de valores, aspectos e atos, pois é através dela que se norteia a maneira como agirmos diante do mundo e dos acontecimentos. Para Maher (2007), nós não herdamos a cultura porque ela é uma construção discursiva. Nessa perspectiva, a cultura faz parte de um processo em constante movimento que se modifica a cada dia por forças externas. Nas palavras de Maher:

E se as culturas não são fixas, não são unas, elas tampouco são irredutíveis. Muito pelo contrário: as culturas são absolutamente permeáveis umas às outras. E isso vale para todas: não é como se houvesse, de um lado, cultura 'puras' e de outro, cultura 'já contaminadas, culturas 'mestiças' (MAHER, 2007, p.263).

Com relação ao ensino de línguas, o fenômeno da aprendizagem ou uso de uma nova cultura através da língua não requer que o aprendiz abandone sua cultura de origem. Para tanto, a abordagem intercultural proporciona a capacidade de aceitar as diversidades, como afirma Silveira:

Segundo a visão interculturalista, entende-se que ensinar/aprender outra língua não é aculturar o aluno, na medida em que ele não é levado a assimilar a cultura da língua-alvo, mas sim enriquecê-lo, pois ele é, ao mesmo tempo levado a consciência de suas próprias identidades (SILVEIRA, 1998, p. 11).

Sobre identidade, Rajagopalan (1998) explica que há diferenças mútuas entre as identidades da língua e do indivíduo que faz uso dela de acordo com a forma como ele evolui, enquanto sujeito, através de seu uso. O autor aponta que os indivíduos constroem suas identidades na língua e por meio delas, partindo do pressuposto de que não existe identidade fixa nem fora da língua, portanto, as identidades são fluídas. 
Contudo, em um ambiente de aprendizagem, mais especificamente com foco no uso da língua portuguesa por indígenas em situação de refúgio, devem-se desenvolver práticas comunicativas significativas e para tanto, se faz necessário buscar a compreensão do processo socio-histórico dos sujeitos, do processo em que se constituem através das línguas que utilizam, de como se constroem mentalmente na multiplicidade da natureza das relações humanas, através da comunicação, já que estas são complexas em quaisquer espaços, de modo a ressignificar diferenças e adequá-las em seus costumes, segundo cada especificidade reivindicada e registrada nas experiências comunicativas do indivíduo.

\section{Contexto de isolamento}

Sobre o cenário das migrações e das fronteiras em face ao fenômeno atual dos refugiados, apontamos algumas reflexões levantadas por Agier (2009) que, a partir do registro de eventos sobre gestões e ações direcionadas a essas pessoas em contexto humanitário, cita exemplos dos campos de agrupamentos em diversos lugares, buscando contextualizar o entorno vivenciado por indivíduos em situação de refúgio. $\mathrm{O}$ autor define essas populações como "reféns da confusão crescente", gerada por situações que acabam por torná-lo um sujeito sem estatuto, deslocado e refugiado em um não-lugar, em meio a eventos permeados de interesses opostos daqueles que intervém de alguma forma para criar mecanismos de controle e gestão dessas populações.

Agier (2009) defende que o dispositivo humanitário é conteúdo da própria intervenção instaurada e refere-se a ele como sendo a mão esquerda diante dos homólogos mundiais e atuais que, segundo o autor, possuem duas mãos do Estado, uma que intervém e a outra que controla sob a justificativa da necessidade de conter para cuidar, criando sociedades de controle sob a guarda da ajuda humanitária. Essa intervenção e controle mencionada pelo acima é visível na organização do abrigo de Pacaraima, até mesmo no motivo pelo qual foi construído, para tirar os indígenas das ruas da cidade. Para Agier, indivíduos em situação de refúgio são induzidos a uma forma de isolamento:

\footnotetext{
os sítios humanitários situam-se nas margens, afastadas dos locais de vida comuns, nos limiares da vida social e da vida, simplesmente. Esses limiares têm uma forma [...] todas essas formas, por diversas que sejam, compõem com os campos de refugiados um conjunto de espaços, hoje em crescimento, para manter refugiados, "clandestinos" e indesejáveis à espera, em sobrevivência e sem direitos. Encerrados no exterior, são espaços de exceção (AGIER, 2009, p. 199).
}

Em outras palavras, estamos diante de sujeito sem estatuto, sem voz, sem autonomia, dependente de níveis e status de vulnerabilidade para garantir sua mínima sobrevivência, que acabam desenvolvendo atividades paralelas na clandestinidade, despojado de toda sociabilidade, acantonados, gerando situações recorrentes sobre o que o autor denomina como gestão dos indesejáveis, "restos do sistema econômico e social mundial" (AGIER, 2009, p. 210). Ainda nas palavras de Agier (2009, p. 211), "a situação dos refugiados rompe a continuidade entre o homem e o cidadão", e seu cenário intersocial é muito mais complexo, como se sua sobrevivência dependesse do fato de não possuírem inscrição nacional, ou como se não estivessem mais no mundo. A única política de vida resistente entre essas pessoas seria as relações criadas nesses não-lugares constituídas de seu próprio espaço-tempo. Relações que, no caso dos indígenas da etnia Warao atendidos no Abrigo 
Janokoida, podem ser ampliadas para além dos perímetros do abrigo, amenizando a condição de refugiado.

Conforme apontado por Almeida Santos et al (2018), a chegada dos indígenas warao ao Brasil (a partir de 2016) gerou, por parte das instituições, grandes questionamentos sobre qual procedimento seguir e, no âmbito das políticas migratórias foi um desafio, devido, principalmente, às características culturais dessa etnia. Os autores supracitados apontam que: "nem o estado brasileiro nem as organizações internacionais tinham referência prévia de como lidar com a situação". Assim, tentaram mantê-los em abrigos ou como diz Agier, em isolamento; porém, essa tarefa torna-se cada vez mais difícil por causa da cultura nômade do povo warao.

De acordo com Almeida Santos et al, os Warao não viajam sozinhos. Eles usam as chamadas redes migratórias que podem ser montadas por parentesco ou por grupos formados ao longo do caminho. Assim, vão organizando as estratégias de fixação e mobilidade que definem também as lideranças. Contudo, dentro da 'confusão' citada por Agier (2009), os waraos conseguem articular suas redes migratórias de forma bem organizadas.

\section{CARACTERÍsticas do POVO WARAO}

O topônimo mais antigo do Rio Orinoco é "Wirinoko" ou "Uorinoko", que significa "lugar onde se rema". Do mesmo modo, a palavra Warao é uma autodenominação que na língua originária deste povo significa "habitante da água" ("waha": ribeira, "arao": gente) ou "povo das águas". Assim, o povo warao habita há séculos o delta do Rio Orinoco, no Estado Delta Amacuro, ao norte da Venezuela. No último Censo Nacional da Venezuela foram registrados 36.027 indivíduos da etnia Warao, dos quais 28.066 expressaram ser falantes da LW, enquanto 3.189 declararam falar apenas espanhol e 872 não declararam nada.

De acordo com o INE - Instituto Nacional de Estatística da Venezuela, os Warao são o grupo humano mais antigo da Venezuela. Estudos arqueológicos sugerem que sua existência tem aproximadamente 7 a 8 mil anos. A tradição de narrativas dessa etnia remonta que eles chegaram ao Delta Amacuro vindos de Trinidad, quando a Ilha de Trinidad estava ainda unida à terra firme. Alguns autores baseiam-se em pesquisas sobre cerâmicas surgidas no município La Horqueta, as quais localizam essa cultura em torno de 17.000 a.C. Ainda assim, as principais informações sobre esse grupo étnico foram registradas com a chegada dos primeiros europeus entre os séculos XV e XVI e, segundo seus registros, descrevem-na como uma cultura adaptada ao meio ambiente aquático, cujos habitantes viviam em palafitas às margens dos rios, sobrevivendo da pesca, da caça e do extrativismo, explorando as fibras do buriti e com uma habilidade incrível para construir canoas. Estas informações foram constantes durante os cinco séculos que se seguiram. (GARCIA CASTRO, 2000)

Em sua organização familiar o povo warao usa bens materiais de forma comunitária e essa organização que parece invisível, surpreende aos não indígenas que com o propósito de observar seu sistema de vida chegam a conviver com eles. A organização familiar das tribos preserva ações comunitárias, a prole cresce de forma extensiva e sob o mesmo teto vivem tataravós, bisavós, avós, pais, tios, e demais ramificações da família, dispondo dos mesmos meios de produção e usufruindo da mesma vida em comum (RODRIGUEZ \& PARELLO, 2010). Quanto à língua warao, os au-

4 Fonte: INE - Instituto Nacional de Estatística/VE: censo 2011. 
tores supracitados afirmam tratar-se de uma língua isolada, que não apresenta traços comuns com outras línguas originárias, pelo que se denomina como uma língua monolíngue, ou seja, uma língua que não provem de nenhuma outra e cujas origens estão baseadas em si mesma. Não é produto nem evolução de nenhuma outra língua conhecida atual ou extinta. É falada principalmente na Venezuela (nas regiões de Delta Amacuro, Sucre, Monágas), Guiana e Suriname. Linguisticamente esta língua ainda não foi classificada apropriadamente.

Ainda de acordo com Rodriguez e Parelló (2010), a educação quando no ambiente originário das comunidades é feita de maneira informal, sutil e natural, sem obrigatoriedades nem reprimendas. Os mais jovens aprendem observando e imitando os adultos, e segundo o sexo, em suas diferentes tarefas diárias, assimilam as regras morais e sociais ouvindo as narrativas sobre os mitos através dos anciãos, cujas sanções quando infringidas as regras são a vergonha e o desprezo da comunidade. A educação formal ou institucionalizada só é realizada quando os membros da comunidade saem em busca das redes estaduais ou municipais de ensino.

Conforme aponta García Castro (2000), o povo warao iniciou sua mobilidade pelo território venezuelano ainda na década de 1960 devido à intervenção ambiental de agricultores e pecuaristas nas terras habitadas pelos indígenas. Outros motivos causaram a migração dessa população para as áreas urbanas do país, como ausência de assistência médica e falta de infraestrutura nas proximidades das aldeias. Assim, a prática de mendicância das mulheres e crianças da etnia warao já era comum nas ruas da Venezuela e continua sendo usada no Brasil. Dessa forma, podemos afirmar que o indígena warao como sujeito sem estatuto e sem voz (AGIER, 2009) já existia no seu próprio país de origem.

Apesar de viverem em movimento pelas zonas urbanas há muito tempo, sempre mantiveram suas tradições de organização comunitária, os costumes alimentares e de vestimenta feminina, além do uso da língua warao.

\section{Descrevendo o arRanjo metodológico}

Como explicitado na introdução, a pesquisa realizada para este artigo foi desenvolvida no campo da Linguística Aplicada, de modo a alcançar a compreensão dos eventos da linguagem em consonância com seu contexto histórico, e problematizá-los, com foco na percepção que os sujeitos da pesquisa têm da interação linguística e do contexto social em que estão envolvidos (MOITA LOPES, 1996).

Para tanto, foi utilizada como base a pesquisa qualitativa com técnica de observação participativa no ambiente do abrigo. Também foi usada a pesquisa-ação, pois dessa maneira o indivíduo é parte integrante do processo de prática e investigação. A principal motivação para a escolha dessa metodologia se deu pelo fato da pesquisadora estar em contato diário com o objeto de pesquisa, pois: "não se trata apenas de resolver um problema imediato e sim desenvolver a consciência coletiva no plano político ou cultural a respeito dos problemas importantes que enfrentam, mesmo quando não se veem soluções em curto prazo”. (THIOLLENT, 2013 p. 18). Assim, essa abordagem metodologia foi possível porque a pesquisadora autora deste estudo também era funcionária do abrigo, o que facilitou as observações e a oferta da oficina de língua portuguesa direcionada às mulheres artesãs da etnia Warao, residentes no abrigo Janokoida. 
O Abrigo Janokoida foi inaugurado no dia 7 de novembro de 2017 em local cedido pelo governo de Roraima, coordenado pela Secretaria de Assistência social do município de Pacaraima juntamente com a Fraternidade Humanitária Internacional- FHI, para atender imigrantes indígenas da etnia Warao que moravam nas ruas do município. Está localizado dentro da zona urbana do município de Pacaraima e atende uma média de 480 imigrantes, todos da etnia Warao de todas as idades, esse número é variável pois muitos retornam ao seu país de origem ou seguem para outras regiões do Brasil. Um dos motivos de regresso à Venezuela é levar mantimentos, roupas, medicamentos, visitar ou trazer familiares que ainda moram lá.

$\mathrm{Na}$ primeira quinzena de dezembro de 2017 foi instalada uma equipe da Setrabes (uma, assistente, uma psicóloga, dois agentes sócio-instrutores e um coordenador), para atender os imigrantes na área socioassistencial. Em março de 2018 instalou-se, em todos os abrigos de Roraima, a Força-Tarefa Logística e Humanitária ${ }^{5}$ chamada Operação Acolhida, em que o Exército Brasileiro colabora na logística das acomodações, alimentos, manutenção de banheiros, lavanderia, agilização de atendimento médico e segurança patrimonial, além do resguardo da integridade física e da convivência com os imigrantes venezuelanos.

No que tange à sua estrutura, o Abrigo Janokoida compreende uma área para o redário (estrutura de ferro que comporta várias redes), cozinha coletiva onde as mulheres elaboram suas refeições, banheiros, lavanderia com pias, sala de vídeo e um espaço onde foi improvisado um campo de vôlei. Há também três contêineres, os quais comportam a equipe do Exército Brasileiro, a administração da Fraternidade Humanitária Internacional e a Equipe da SETRABES, o último contêiner funciona como ambulatório da equipe de saúde para consultas, remoções e atendimento ambulatorial geral.

Dentro do Abrigo Janokoida os indígenas Waraos estão organizados por grupos liderados pelos "Aidamos/Caciques", esses são compostos muitas vezes por familiares. As lideranças são eleitas via assembleias, as quais discutem melhorias aos abrigados. Cada grupo possui seus Aidamos. Com relação a isso, Rodriguez e Parelló (2010, p.35) apontam que, “en el ámbito político, en sus orígenes los Warao se encontraban orientados bajo la influencia de un hombre mayor y experimentado que en su idioma denominan: "aidamo", "araobo" o "idamo"; cuyo significado es el jefe, el más anciano".

O Abrigo Janokoida tem um aspecto diferenciado dos outros abrigos construídos para atender os imigrantes venezuelanos em situação de vulnerabilidade social, as refeições são feitas pelas mulheres Waraos e elas cozinham com fogo a lenha. As mulheres acordam cedo e vão tirar lenha na mata para poder preparar suas refeições, marca importante de sua cultura.

Dentre os moradores do Abrigo Janokoida, até novembro de 2018, havia em torno de 80 mulheres artesãs, mas o público escolhido como amostragem para este trabalho foi de vinte artesãs, as quais afirmavam ter escolaridade entre Ensino Fundamental I e Médio, com idades entre 30 e 60 anos, participantes das oficinas de Português voltadas para a comunicação em situação de comercialização. ${ }^{6}$ Por essa razão, o público escolhido para participar das oficinas de aprendizagem de português foi de mulheres artesãs.

5 Cf. http://bit.ly/36NpAzz. Acessado em 24 fev. 2019.

6 As mulheres warao fazem o artesanato dentro do abrigo e comercializam para visitantes ou para a comunidade local. 


\section{Dos AMbientes de USO DA Língua PORTUguesa}

$\mathrm{O}$ ambiente fronteiriço apresenta características de intenso contato entre as línguas portuguesa e espanhola, o que, possivelmente, minimiza o interesse para aprender ou fazer uso da língua portuguesa, pois há vários espaços para abertura de comunicação nas duas línguas, com algumas diferenças importantes entre os grupos de indígenas abrigados.

A convivência diária e o trato com os moradores do abrigo nos levaram a observar que os homens, por exemplo, têm maior contato com a língua portuguesa, pois eles saem do abrigo para exercer trabalhos avulsos com comerciantes do município ou para prestar serviço de forma geral à comunidade local, consequentemente, o ambiente de comunicação em língua portuguesa proporciona-lhes maior entendimento. Quanto às mulheres, seu ambiente de uso e comunicação em língua portuguesa é mais restrito, pois elas passam a maior parte do tempo dentro do abrigo.

Em contrapartida, as crianças têm mais oportunidades de aprender visto que fazem parte de um projeto chamado Bem Comum7, em que há aulas de português como disciplina semanal com professores brasileiros, nesse projeto as crianças desenvolvem e aprendem de forma lúdica as línguas maternas (Warao e Espanhol) e a língua portuguesa.

Tendo em vista o pouco contato com a comunidade e com a língua portuguesa, planejamos as oficinas com o intuito de facilitar a comunicação, a inserção e o protagonismo feminino, tendo como base a língua, não só como um meio de comunicação para comercializar os artesanatos, mas também como forma de acolhimento nesse contexto migratório.

\section{Oficinas de língua portuguesa}

Nesta subseção descrevemos pontos relevantes da construção do estudo, tomando como base as oficinas ministradas para mulheres artesãs indígenas da etnia Warao que vivem no abrigo Janokoida. Essa sequência de oficinas foi planejada de maneira que as mulheres pudessem se comunicar em língua portuguesa no ato de compra e venda de seus artesanatos.

As atividades também foram planejadas com o intuito de aproximar as cursistas indígenas em situação de refúgio e possibilitar que conhecessem que, além de uma língua "difícil” de aprender, há também uma cultura brasileira diversificada. Neste sentido, o projeto visou contribuir tanto para o aprimoramento da competência linguístico-cultural quanto para a aprendizagem cidadã e significativa da língua portuguesa pelas artesãs indígenas do abrigo.

O conteúdo trabalhado com as alunas estava voltado para as noções básicas da língua portuguesa, assim como normas de cortesias; alfabeto; geografia do Brasil e suas peculiaridades; ampliação do vocabulário de materiais utilizados para a fabricação do artesanato Warao e situações de conversação para venda de artesanato.

Esses conteúdos foram trabalhados de forma dinâmica para que houvesse maior aproveitamento e aprendizado das cursistas, as aulas se deram no turno vespertino, dentro do abrigo, em um espaço que é utilizado para descontração dos moradores, em uma sala de vídeo com televisão como ferramenta pedagógica e um quadro improvisado em MDS (Medium Density Fiberboard). As aulas se

\footnotetext{
7 O projeto Bem Comum de educação para integração transcultural foi elaborado em parceria entre Educadores Warao, Paróquia de Pacaraima Jesus Peregrino, Abrigo Janokoida, SETRABES (Secretaria de Trabalho e Bem Estar Social), UNICEF, Associação Cultural Canarinhos da Amazônia, Fraternidade - Federação Humanitária Internacional, Vicariato Apostólico del Caroni, Irmãs Escalabrinianas e Universidade Pedagógica Experimental Libertadora (UPEL), visando o ensino transcultural das crianças e jovens atendidos diariamente na paróquia de Pacaraima/RR.
} 
deram dentro da sala de vídeo onde não havia cadeiras ou mesas, o pedaço de MDF serviu como quadro branco e a televisão para apresentação em slides. As aulas tiveram duração aproximada de 2 horas e meia, por cinco dias. Assim, a partir dos dados levantados durante a realização das oficinas foi possível desenvolver a discussão e a análise da pesquisa.

\section{Discussão e RESUltados}

Nesta seção discorremos sobre o passo a passo e as impressões relevantes de cada momento vivido durante as oficinas. Abordamos alguns pontos relevantes observados antes e durante a execução das aulas, que contribuíram na prática e aprendizagem docente. As oficinas de uso da língua portuguesa foram planejadas de forma sequencial. No $1^{\circ}$ dia vimos as normas de Cortesias/ Apresentações/ Alfabeto/ história da língua portuguesa, da seguinte forma: após a apresentação da oficina, foi explicado o tempo de duração e o principal objetivo que era fazer com que elas conseguissem se expressar para vender seus artesanatos aos visitantes brasileiros do abrigo. Em seguida, foi feita uma breve apresentação oral da origem da língua portuguesa. Nesse primeiro contato, apesar de falar pausadamente, a compreensão foi pouca, mas a mediação foi possível com o uso da tradução, para melhor entendimento.

Em seguida foi apresentado o alfabeto e logo surgiram as curiosidades das letras diferentes como o "c", porém, quando surgiu a dúvida, elas começaram a conversar entre si em warao, sendo necessário um tempo maior de explicação para cada letra. Após explicar algumas peculiaridades da língua portuguesa, começamos com as normas de cortesia. Para essa etapa foi feita uma dinâmica com diálogo de apresentação entre elas, usando as cortesias aprendidas no dia. Finalizamos a aula com a música "Sinal fechado", de Paulinho da Viola.

Foram vários desafios desde o primeiro dia. Durante uma explicação e outra algumas delas saiam porque tinham que cuidar do filho ou porque precisavam fazer comida. Assim, a aula que começou com 12 alunas (mesmo com 20 inscritas) terminou apenas com 6 . Nesse dia teve também como fato relevante uma grande reunião com a coordenação para tratar de assuntos referentes à convivência dos abrigados.

No segundo dia a aula foi sobre as Regiões do Brasil, os pronomes pessoais e verbo ser. $\mathrm{O}$ início seu deu relembrando as normas de cortesias e alguns diálogos, a dinâmica com esse conteúdo foi através de repetição e reescrita dos diálogos de acordo com a pronuncia. Por exemplo: o "bom dia" reescrito como "bom yia", e assim elas começaram a dialogar conforme os exemplos. Em seguida foi realizada a explanação sobre as regiões do Brasil e seus pontos turísticos, assim como as manifestações culturais de cada região. Nesse momento, elas ficaram encantadas com a diversidade do Brasil, ao perguntar se conheciam essas regiões ou imaginavam que o Brasil era tão grande, elas responderam que estavam encantadas com tantas coisas bonitas. Foram mostrados também os estados em que há indígenas warao e, ao indagá-las sobre quererem ir para outros lugares, elas responderam que não e que gostam do lugar onde vivem e esperam que o governo Venezuelano melhore para que possam retornar ao seu país de origem. Nesse momento foi possível perceber o sentimento nostálgico e esperançoso de voltar para casa, algumas afirmaram que estavam no abrigo apenas para poder acumular alimentos para enviar para familiares na Venezuela, outras que decidiram ficar no abrigo provisoriamente para juntar dinheiro vendendo artesanato e poderem retornar a suas comunidades de origem quando a situação melhorar no país. Nesse sentido, uma 
das principais causas da desmotivação em aprender a língua portuguesa se pauta no pensamento de que não irão permanecer por muito tempo no Brasil, pois pretendem retornar ao país de origem.

Contudo, a aula mais uma vez terminou com poucas mulheres artesãs, houve um encontro com a pastoral da criança, no qual as mães deveriam participar, pois se tratava de assuntos relacionados à saúde das crianças. Conforme relatado, as mulheres saíram das aulas por estarem sempre ocupadas com seus afazeres de cuidar dos filhos e das tarefas domésticas, sobre essas responsabilidades, Souza et al (2018) traz uma narrativa de um warao que descreve as principais obrigações das mulheres:

Primero es los cuidados de la casa, con los niños, también trabajan en la agricultura, en
la artesanía, ese es o único trabajo que hay en parte de los warao, hacen cesta, chichorro,
sombrero, tenemos cuidado con que hacemos. Son trabajos de los warao. Los hombres,
pescan, siembran, por ejemplo nosotros decimos ocumo chino, que es parte de la comida
de los warao, gracias al ocumo nosotros vivimos allí en nuestra tierra. Las mujeres llevan
los niños a la escuela, enseñan las tareas de casa para las niñas, ya los hombres enseñan
para los niños la agricultura, la siembra, la pesca y la artesanía (SOUZA [et al], 2018,
p.1441).

O trecho destacado acima relata as ocupações das mulheres warao no cuidado dos filhos, da casa e também o trabalho na agricultura e no artesanato. No Brasil, as warao ainda não trabalham com agricultura, mas realizam as outras atividades citadas. Assim, além de cuidarem da casa (abrigo) e das crianças, as warao fazem artesanato, parte importante de suas atividades diárias, por isso foi o tema da terceira aula.

No terceiro dia ampliamos o vocabulário (acessório, vestuário e material utilizados no artesanato warao). Essa aula foi muito proveitosa, pois fomos construindo um pequeno dicionário com alguns nomes de acessórios e vestuário relevantes para a comunicação com os brasileiros e simulamos uma situação em que elas tinham que empregar o nome do acessório ou vestimenta. Pedimos também que explicassem de que material é feito o artesanato warao, e assim, fomos construindo diálogos interculturais que se tornaram significativos na vida cotidiana de todos nós; no entanto, no meio da aula tivemos que parar a explicação, pois iria chegar uma visita para comprar artesanato e todas elas saíram para vender. Sobre o lugar da cultura no ensino de línguas, Almeida Filho afirma que:

\footnotetext{
Así, podemos imaginar que lo cultural en un ambiente de aprendizaje comunicativo necesita atravesar el límite de la propia cultura (donde tenemos ahí el sentido de lo transcultural) cuando la conciencia de ello lo permita, e instalarse en lo intercultural, que implica la reciprocidad de vivir (aunque sea temporariamente) en la esfera cultural del otro y simultáneamente tener al otro confortablemente en nuestra esfera de cultura (ALMEIDA FILHO, 2002, p. 211).
}

Dessa maneira, o ambiente em que se deu a interculturalidade nos permitiu ir além do ensino de língua portuguesa para fins de comercialização de artesanato, fazendo com que houvesse a reciprocidade cultural. Esse aspecto ficou claro quando elas ensinaram sobre como o artesanato warao é feito, a origem dos materiais usados e as tradições étnico-culturais.

No quarto dia retomamos os assuntos das aulas anteriores, apresentamos dois modelos de diálogos que simulavam situações de compra e venda e fomos praticando juntos, e aprendendo a 
pronunciar as palavras novas na língua portuguesa. Durante a aula foram surgindo novas formas de interação real em LP. No quinto e último dia foi a aula prática de tudo o que elas aprenderam durante os quatro dias anteriores, momento em que chamamos as 5 alunas que permaneceram até o final para um desafio: convidamos alguns militares para conversarem em língua portuguesa, com algumas perguntas chaves como: "quanto custa? Tem mais desse? Tem troco? De que material é feito esse artesanato?" E montamos uma feirinha com os artigos e acessórios estudados na aula anterior e assim, concluímos nossa sequência de oficinas.

As atividades de interação em LP fizeram com que as artesãs fossem instigadas a usar a língua portuguesa em contexto real de venda de seus produtos, portanto, o ensino tornou-se significativo (ALMEIDA FILHO, 2007) para nossas alunas.

Entretanto, notamos que, razões como permanência provisória no abrigo, as responsabilidades domésticas de cuidar dos filhos, fazer comida, lavar roupa, entre outros imprevistos que ocorreram todos os dias, como as reuniões e visitas, dificultaram a permanência delas nas aulas que desmotivaram as artesãs em aprender LP. Talvez pela educação e cultura da referida etnia, na qual as mulheres devem assumir majoritariamente as funções domésticas e obrigações familiares do cuidado e resguardo do convívio. Nesse sentido, Rodriguez e Parello (2010) defendem que a mulher Warao, ao se casar, por volta dos quinze anos de idade, geralmente torna-se a dona da casa, tomando para si as obrigações de administração das economias, redistribuição da caça, colheita do marido, no cuidado dos filhos e alimentação da família.

Durante as oficinas foi notória a desmotivação da maioria, pois começamos com vinte artesãs inscritas e terminamos com cinco cursista, sendo apenas três artesãs. Souza et al também aponta a mesma dificuldade em ensinar as mulheres warao no abrigo de Boa Vista:

\footnotetext{
Na segunda visita, no dia 17/04, chegamos e eles estavam fazendo a oração do dia, falamos com o responsável da ONG que estávamos ali para fazer oficinas com os imigrantes, então ele conversou com alguns líderes. Mas como estavam preocupados em preencher os formulários de pedido de refúgio, fazer o almoço e a limpeza do ambiente, tivemos dificuldade em reunir nosso público-alvo principal: as mulheres [...] No dia 18/03, [...] o líder nos informou que as mesmas haviam saído para vender seus artesanatos e pedir dinheiro, apenas duas que se propuseram a participar e o líder do grupo também queria compartilhar sua cultura e seus costumes conosco (SOUZA [et al, p. 1440-1441).
}

Cabe ressaltar que as que seguiram até o final da oficina se sentiram gratas e uma delas relatou, dias depois, que quando montaram a feirinha e chegou uma visita para olhar os artesanatos, ela já foi logo dizendo "essa cesta é feita de fibra de buriti". Falou com orgulho e satisfação, dizendo também que a visitante ficou surpresa com o português dela. Com relação a isso, Trouche (2002) diz que "o aprendiz passa a tomar conhecimento de uma memória afetiva que estabelece os vínculos socais e cria o sentimento de pertença em determinado grupo social”.

\section{CONSIDERAÇÕES FINAIS}

Retomando a problematização da pesquisa que originou este artigo: quais são as necessidades de aprendizagem e uso da língua portuguesa por mulheres imigrantes indígenas da etnia Warao, abrigadas em Pacaraima/RR? Tal indagação conduziu-nos a muitas esferas de debate, porém, nossas percepções para tal resposta partiram de um grupo de artesãs estrangeiras que participaram 
da oficina. Nesse sentido, foi possível perceber que a procura e a necessidade em aprender LP é pouca, apesar de estarem residindo em um país cuja língua oficial é o português, a grande maioria das artesãs warao não têm interesse em aprendê-la.

Considerando o contexto plurilíngue em que essas mulheres estão inseridas, somado ao fato dos costumes da etnia warao ainda serem bastante fortes em suas vidas cotidianas, a aprendizagem da língua portuguesa é irrelevante, pois todos fazem a mediação com a língua espanhola para a comunicação com os brasileiros, e por estar em uma localidade fronteiriça o contato e o fluxo das duas línguas é muito recorrente, haja visto que, as pessoas que não falam o espanhol fluente, fazem uso da translinguagem por meio dos repertórios linguísticos que possuem.

Constatamos também que as mulheres artesãs têm pouco contato com a comunidade, devido à responsabilidade com a organização da família dentro do abrigo, característica própria dessa etnia, segundo Rodriguez e Parelló (2010). Esses apontamentos surgiram desde a primeira aula, na qual apenas 12 mulheres, de vinte inscritas, compareceram no horário e local marcado, regularmente. Em conversa informal percebemos que havia sempre uma desculpa para o não comparecimento na oficina, talvez pela ideia constante de utilização do refúgio com fins de uso provisório e transitório. Sempre havia algo mais importante do que aprender e usar a LP. De certo modo, em alguns momentos, essa atitude pareceu uma forma de proteção, de resguardo de suas referências identitárias originais, como se, ao terem clara a ideia de retorno às suas casas, quisessem se manter iguais ao retornar, sem riscos de perdas de seus costumes ou formas de comunicação originárias, uma percepção que apontamos como possível foco de novos estudos específicos.

Vale enfatizar ainda que, o ensino se deu para falantes de língua materna warao, que têm o espanhol como segunda língua, sendo que o conhecimento dessas falantes se restringe a essas duas línguas, pois elas continuaram mantendo pouco contato com o português, já que saem pouco e quase não interagem com a comunidade local. Elas passam o dia cuidando dos filhos, fazendo comida e artesanato. Cabe ressaltar também que a maioria dos funcionários do abrigo fala espanhol durante o trabalho, de modo a facilitar a comunicação, fato que dificulta ainda mais o interesse pelo uso da língua portuguesa.

\section{REFERÊNCIAS}

AGIER, M. Refugiados diante da nova ordem mundial. Tempo Social. Revista de sociologia da USP, v. 18, n. 2, 2009, p. 197-215.

ALMEIDA FILHO, J. C. P. Língua além de cultura ou além de cultura, língua? Aspectos do ensino de interculturalidade. In: CUNHA, Maria Jandyra Cavalcanti; SANTOS, Percília. Tópicos em Português Língua Estrangeira. Brasilia: Editora UNB, 2002. p. 209-215.

. Dimensões comunicativas no ensino de línguas. Campinas, SP: Pontes Editora, $4^{a}$ Edição, 2007. ALMEIDA SANTOS, S. M; ORTOLAN, M. H; SILVA, S. A. "Índios imigrantes" ou "imigrantes índios"? Os Warao no Brasil e a necessidade de políticas migratórias indigenistas. Trabalho apresentado na $31^{\mathrm{a}}$ Reunião Brasileira de Antropologia. Brasília/DF, 2018.

BORTONI-RICARDO, S. M. O professor pesquisador: introdução à pesquisa qualitativa - São Paulo: Parábola Editorial, 2008.

GARCIA CASTRO, A. Mendicidad indigena: Los Warao Urbanos. Boletin Antropológico, n. 48, 2000, pp. 79-90. MAHER, T. M. Educação do Entorno para a Interculturalidade e o Plurilinguismo. In: Kleiman e Cavalcanti. (Org.). Linguística Aplicada - suas faces e interfaces. Campinas, SP: Mercado de Letras, 2007, p. 255-270. 
MATOS, F. G. "Como usar uma linguagem humanizadora: orientação para professores de línguas estrangeiras”. In MOTA, K.; SCHEYERL, D. (Orgs.) Recortes interculturais na sala de Línguas Estrangeiras. Salvador: Editora da UFBA, 2004.

MOITA LOPES, L. Oficina de Linguística Aplicada: afinal, o que é Linguística Aplicada? Campinas, SP: Mercado das Letras, 1996.

RAJAGOPALAN, K. O conceito de identidade em linguística: é chegada a hora para uma reconsideração radical? Trad. de PISSETA, A. In: SIGNORINI I. (Org.). Língua(gem) e identidade: elementos para uma discussão no campo aplicado. Campinas: Mercado das Letras, 1998.

RICHARDSON, R. J. Pesquisa social: métodos e técnicas. 3. ed., São Paulo: Editora Atlas, 2007.

RODRÍGUEZ, M; PARELLO, J. (2010). Diseño de una ruta turística de interpretación Cultural para la promoción y el desarrollo local de la etnia aborigen warao en el Estado Delta Amacuro, Venezuela. (Tesis de Maestría). Universidad de la Habana. Caracas, Venezuela.

SILVEIRA, R. C. P. (org.). Português língua estrangeira perspectivas. São Paulo: Cortez, 1998. 119p

SOUZA, M. B.; PEQUENO, A. S.; COTA, D. S.; SAMPAIO, J. S. O papel da mulher Warao nas relações de poder comunitárias. Revista Philologus. Ano 24, n. 72. Rio de Janeiro: CiFEFiL, set./dez.2018.

THIOLLENT, M. Metodologia da pesquisa-ação. 12. ed. São Paulo: Cortez, 2013.

TROUCHE, L. M. C. Ensino de Português - Língua Estrangeira - Interface com aspectos socioculturais. In: JÚDICE, N. (Org.). Português como estrangeira: perspectiva de quem ensina. Niterói: Intertexto, 2002, p. $81-92$. 